\title{
Indicadores referentes à qualidade em centros da Rede Nacional de Pesquisa Clínica
}

\author{
Evaluation of quality-related indexes in National Clinical Research Network Centers
}

Gabriela Gimenez Faustino Ilana1, Monica Akissue de C Teixeira Cintra², André Lucirton Costa ${ }^{3}$, Eduardo Barbosa Coelho ${ }^{4}$

\begin{abstract}
RESUMO
Modelo do estudo: Estudo transversal nos 32 centros participantes da Rede Nacional de Pesquisa Clínica (RNPC). Objetivos: Desenvolver e validar um questionário eletrônico capaz de medir o desempenho dos centros participantes da RNPC em uma auditoria de qualidade baseada nas Boas Práticas Clínicas (BPC). Avaliar a correlação do instrumento com o guia de inspeção em BPC disposto na Instrução Normativa no 4, de 11/05/09 da ANVISA (IN4/ANVISA) e verificar, por meio do questionário desenvolvido, o desempenho dos centros participantes da RNPC, em relação ao atendimento a requisitos de um sistema de gestão da qualidade (SGQ). Métodos: Foi aplicado um questionário eletrônico, legitimado por uma validação de conteúdo. As questões foram agrupadas em três domínios, infraestrutura, estrutura organizacional e processos. Os dados foram pontuados de acordo com o cumprimento (1) ou não cumprimento (0) em BPC. As questões do questionário foram arbitrariamente correlacionadas aos itens da IN4, atribuído (0) ponto às questões conformes e (1) para não conforme. O índice de cumprimento para atendimento aos itens críticos e maiores (ICCM) foi calculado para cada domínio usando a equação ICCM = 1 * (Escore IN4) + valor total escore para dado domínio. As comparações foram feitas por teste de Kruskal-Wallis e teste de Spermann, considerando $\mathrm{P}$ valor $<0,05$. Resultados: $O$ instrumento representa aproximadamente $40 \%$ dos itens do roteiro de inspeção da IN4/ANVISA. A pontuação obtida com o questionário correlaciona-se significativamente ao escore correspondente à IN4/ANVISA ( $r=0,95$, $0,89$ a $0,98, I C 95 \%, P<0.0001)$. A mediana do ICCM foi menor que $75 \%$ em todos os domínios estudados. Conclusões: $O$ instrumento desenvolvido para medir o desempenho em BPC apresenta alta correlação com a IN4/ANVISA e poderia ser utilizado para auditoria interna de qualidade. A classificação para itens críticos e maiores definidas pela IN4/ANVISA mostrou-se muito restritiva e necessita ser adequada a realidade dos centros de pesquisa nacionais.
\end{abstract}

Palavras-chave: Centros de Pesquisa Clínica, Gestão da Qualidade, Rede Nacional de Pesquisa Clínica, Brasil.

1. Mestra em Ciências, Programa de Gestão de Organizações de Saúde, Faculdade de Medicina de Ribeirão Preto - Universidade de São Paulo (FMRP-USP). Assistente Técnica na Unidade de Pesquisa Clínica do Hospital das Clínicas da FMRP-USP.

2. Doutora em Pesquisa Clínica em Doenças Infecciosas. Gerente administrativa da Unidade de Pesquisa Clínica do Hospital das Clínicas da FMRP-USP.

3. Professor Associado da Faculdade de Economia, Administração e Contabilidade de Ribeirão Preto - USP.

4. Professor Associado do Departamento de Clínica Médica daFMRP-USP. Coordenador Técnico Cientifico da Unidade de Pesquisa Clínica do HCFMRP-USP.
CORRESPONDÊNCIA: Gabriela Gimenez Faustino Ilana Unidade de Pesquisa Clínica - UPC Campus Universitário s/n - Monte Alegre 14048-900 - Ribeirão Preto SP ggfaustino@gmail.com

Recebido em 13/04/2017 Aprovado em 10/04/2018 


\begin{abstract}
Study design: A transversal study that evaluated 32 Clinical research centers (CRC) of the National Clinical Research Network (Rede Nacional de Pesquisa Clínica/RNPC). Objectives: To develop and validate an electronic questionnaire to measure how CRC that are part of the RNPC performed in a quality audit based in Good Clinical Practice, to evaluate the correlation between our instrument and IN4/ANVISA guide and to access the quality of the CRC. Methods: An electronic questionnaire was applied and validated by contend valid index. The questions were divided into tree domains, infrastructure (I), organization structure (OS) and process (P). Data were scored according compliance (1) or non-compliance (0) with GCP. The questions of our questionnaires where arbitrary related to IN4/ANVISA guide and scored as non-conformity (1) or conformity (0). The indexes of compliance in critical and major items (ICCM) were calculated using the equation: ICCM = $1 *$ (IN4 score) + total score for the domain. The correlation of the two measurements above was done using Kruskal-Wallis and Spearman rank method, considering $\mathrm{P}<0.05$. Results: The questionnaire represents about $40 \%$ of the IN\$/ANVISA document. The score obtained with the questionnaire had a significant correlation to IN4/ ANVISA score $(r=0.95,0.89$ to $0.98, \mathrm{Cl} 95 \%, \mathrm{P}<0.0001)$. The median ICCM was less than $75 \%$ for all domain studied. Conclusion: The instrument designed to measure performance GCP showed high correlation with IN4/ ANVISA guide and could be used to perform the internal quality audit of a CRC. The IN4/ANVISA guide showed to be very strict and might be necessary to review it and adequate to the reality of nationals centers.
\end{abstract}

Keywords: Clinical Research Centers, Quality Management, National Clinical Research Network, Quality Manager, Brazil.

\section{INTRODUÇÃO}

Nas últimas décadas é crescente o desenvolvimento de instruções, normativas, regulamentos e diretrizes sobre pesquisa clínica, definida como "qualquer investigação em seres humanos, objetivando descobrir ou verificar os efeitos farmacodinâmicos, farmacológicos, clínicos e/ou outros efeitos de produto(s) e/ou identificar reações adversas ao produto(s) em investigação, com o objetivo de averiguar sua segurança e/ou eficácia". ${ }^{1}$ A regulamentação contínua é necessária para que haja o aperfeiçoamento de mecanismos que visam proteger os participantes de pesquisas, não sendo tolerada a carência da ética na pesquisa e ciência. ${ }^{2}$

Cada país ou bloco comercial desenvolveu sua própria estrutura legal para a proteção de participantes em pesquisas. Entretanto, a maioria dos países desenvolvidos, responsáveis pela maior parte dos novos lançamentos de medicamentos, adotou a Diretriz em Boas Práticas Clínicas (BPC) Documento E6, elaborada na Conferência Internacional de Harmonização (International Conference on Harmonisation- $\mathrm{ICH}$ ) como documento padrão a partir de 1996. Este documento define BPC como "padrão de qualidade científica e ética internacional para o desenho, condução, registro e relato de estudos que envolvam a participação de seres humanos". ${ }^{3}$

Desde a adoção do Manual de Boas Práticas Clínicas da Conferência Internacional de Harmonização, os ensaios clínicos tornaram-se mais complexos devido as mudanças tecnológicas e a globalização, a fim de acompanhar essas mudanças, a Diretriz E6 da ICH, considerada padrãoouro para BPC, sofreu uma revisão, chamada $\mathrm{ICH}$ E6 (R2), em dezembro de 2016, da qual o Brasil, por meio da Agência Nacional de Vigilância Sanitária - ANVISA passou a ser signatário.

Dentre as atualizações mais significativas destacam-se a Gestão da Qualidade, em que o patrocinador deve implementar um sistema de gestão da qualidade ao longo de todo o processo dos ensaios clínicos, como desenho, condução, registro, avaliação, reporte e arquivo. O sistema de gestão da qualidade deve usar uma abordagem baseada em risco, nas seguintes eta- 
pas: identificação crítica de processos e dados, identificação de risco, avaliação, controle, comunicação, análise e relatório de risco. ${ }^{4}$

O desenvolvimento científico e tecnológico, orientado por "padrões de excelência, ética e equidade, é fundamental para o aprimoramento do Sistema Único de Saúde (SUS) e para a melhoria da qualidade de vida da população". ${ }^{4}$ Para atender a este contexto, em 2005, o Ministério da Saúde (MS) e da Ciência e Tecnologia (MCT), lançaram um edital oferecendo apoio financeiro à criação ou consolidação de centros de pesquisa clínica vinculados a hospitais universitários. ${ }^{5}$

A implantação dos 32 centros de pesquisa clínica vinculados a hospitais de ensino das cinco regiões brasileiras disponibilizou uma infraestrutura básica para o desenvolvimento de todas as fases de ensaios clínicos, permitindo que os investigadores clínicos obtenham "conhecimentos científicos referentes a medicamentos, procedimentos ou métodos de abordagem de problemas que afetam a saúde da população". ${ }^{5}$

Para a pesquisa clínica o entendimento de qualidade implica na compreensão dos requisitos de um projeto, produto ou serviço estabelecido pelo patrocinador, e na forma de atender às expectativas. Para isso, o centro de pesquisa deve planejar a execução do protocolo e possuir um plano de contingência em caso de desvios das Boas Práticas Clínicas, assegurando a consistência dos dados, aderência ao protocolo e segurança do participante de pesquisa. ${ }^{6}$

Ainda que as instâncias éticas e sanitárias em pesquisa clínica no Brasil não exijam um certificado de gestão da qualidade para os centros de pesquisa clínica, estes devem estar preparados para o cumprimento dos requerimentos dispostos na Instrução Normativa no 20, de 02 de outubro de 2017, que dispõe sobre procedimentos de inspeção em Boas Práticas Clínicas para ensaios clínicos com medicamentos. Esta Instrução Normativa revoga a IN no 4, de 11/05/2009 da ANVISA (IN4/ANVISA), entretanto, como a IN 20/2017 não publica um roteiro de inspeção, os centros de pesquisa baseiam-se no roteiro disponível na IN no 4, de 11/05/2009 que dispõe sobre o Guia de Inspeção em BPC.

$\mathrm{Na}$ inspeção serão observados os itens descritos em seu roteiro classificados como críti- cos, maiores, menores ou informativos. A depender do relatório da inspeção e da manifestação do patrocinador, a ANVISA poderá declarar no parecer final da inspeção que o estudo está ou não está de acordo com às BPC. ${ }^{7}$

Como visto, na revisão das diretrizes em BPC destaca-se a Gestão da Qualidade, desta forma é fundamental que os centros de pesquisa desenvolvam ferramentas para medir seu desempenho prévio a uma inspeção regulatória, permitindo a deteç̧ão precoce e periódica de problemas relacionados à execução de protocolos em BPC. Ainda, o diagnóstico de falhas em condução de protocolos em BPC pode permitir aos centros a elaboração de um plano de ação para sanar tais desvios, promovendo o aperfeiçoamento e a melhora continua do Sistema de Gestão de Qualidade (SGQ) em pesquisa clínica. Embora fundamentais, tais ferramentas não estão disponíveis para a maioria dos centros da RNPC, sendo desconhecido que haja algum instrumento balizado no Guia de Inspeção em BPC disponível na IN4/ ANVISA.

Portanto, o presente estudo teve como objetivo desenvolver e validar um questionário eletrônico capaz de medir o desempenho dos centros RNPC em uma auditoria de qualidade baseada nas BPC e de acordo com o guia de inspeção publicado pela IN4/ANVISA. Ainda, utilizando, o questionário desenvolvido, avaliou-se o desempenho dos centros participantes da RNPC, em relação ao atendimento a requisitos de um SGQ.

\section{MÉTODOS}

Primeiramente foi elaborado um questionário eletrônico baseado nas BPC tendo como base o documento E6 em BPC (ICH/GCP 1996). Não há um questionário padrão-ouro ou modelo a ser utilizado como comparador, portanto, foi realizada uma validação de conteúdo, onde as perguntas dos questionários foram independentemente avaliadas por um grupo de cinco juízes, caracterizados segundo sexo, idade, tempo de prática em pesquisa clínica, tempo de prática em qualidade e titulação.

Após informados e esclarecidos sobre o objetivo da pesquisa, os juízes foram orientados a classificar todas as perguntas do questionário 
como válidas ou não válidas, e foi calculado um Índice de Validação de Conteúdo. ${ }^{8}$

O questionário inicial era formado por 76 questões que foram avaliadas de forma presencial e individual por cada profissional. Todas as questões foram discutidas com cada juiz e as observações foram registradas.

As observações de todos os juízes foram analisadas pelos pesquisadores, e as perguntas que apresentaram Índice de Validação de Conteúdo (Content Validity Index) CVI igual a 100\% foram mantidas no questionário. As perguntas com CVI menor que $100 \%$ e maior ou igual a $80 \%$ foram discutidas e as perguntas com CVI menor que $80 \%$ foram retiradas do questionário ou sofreram modificação em sua apresentação.

Após a validação, o questionário foi construído em formato eletrônico utilizando o LimeSurvey, Todos os 32 centros da RNPC foram convidados a participar deste estudo transversal e um Termo de Consentimento Livre e Esclarecido (TCLE) foi obtido de cada participante antes da aplicação do questionário (Processo 3233/ 2014, HCFMRP-USP). O link para preenchimento do questionário ficou disponível para coleta dos dados por 5 meses, a partir de setembro de 2014 . A versão final do questionário está disponível no anexo 1.

Para análise dos dados de forma estruturada, cada item do questionário foi arbitrariamente dividido em três domínios diferentes: Estrutura Organizacional (E); Infraestrutura (I) e Processos (P). Os domínios foram divididos baseados nos fundamentos e vocabulários de sistemas de gestão da qualidade apresentado pela Associação Brasileira de Normas Técnicas, NBR ISO 9000, 2005, que define, estrutura organizacional como conjunto de responsabilidades, autoridades e relações entre pessoas; infraestrutura como organização sistema de instalações, equipamentos e serviços necessários para a operação de uma organização e processo como conjunto de atividades inter-relacionadas ou interativas que transformam insumos (entradas) em produtos (saídas). Desta forma, questões relativas a adequação de recursos humanos como a presença de colaboradores ou cargos atrelados as funções pertinentes à pesquisa clínica; politica institucional de treinamento em BPC; experiência do centro em con- dução de protocolos de pesquisa clinica ou em auditoria externa prévia; presença de manual de qualidade; planos estratégico e presença de plano gerencial foram computadas neste domínio. Por sua vez, o domínio Infraestrutura for relacionado com a adequação de áreas dedicadas à execução de protocolos de pesquisa como enfermarias ou ambulatórios exclusivos, farmácia para armazenamento de produto em investigação, laboratório para processamento, armazenamento e envio de amostras biológicas, setor de arquivamento de documentos e estrutura de apoio de informática para registro de dados clínicos e gerenciamento de projetos de pesquisa clínica. Por fim, o domínio Processos foi atribuído as tratativas administrativas para garantir as normas de BPC como a presença de um Sistema de Gestão da Qualidade (SGQ); certificação de laboratórios; presença de procedimentos operacionais padrão de acordo com a IN4 ANVISA; documentação de garantia dos cumprimentos de normas bioéticas, confidencialidade e segurança de dados; politica para tratamento de eventos adversos e de violação ou desvios de protocolos e metodologia para gerenciar ações corretivas e preventivas. A alocação das questões do formulário desenvolvido com os domínios foram harmonizadas entre dois pesquisadores (GGFI e EBC), podendo haver situações nas quais uma questão pontuasse em mais de um domínio. As eventuais discordâncias entre os dois autores foram desempatadas por uma terceira pesquisadora participante do projeto (MATC).

Os dados do questionário foram pontuados de acordo com o cumprimento (1) ou não cumprimento (0) em BPC. Cada centro recebeu um escore, variando de acordo com o domínio. O escore máximo pontuado no questionário eletrônico para o domínio estrutura organizacional foi de 21 pontos (Emax $=21)$; para Infraestrutura de 17 pontos $(I \max =17)$ e para processos de 32 pontos ( Pmax $=32$ ), sendo o escore total 70 pontos.

As questões do questionário, baseadas no documento E6 de BPC, foram correlacionadas aos itens da IN4/ANVISA. Foi atribuído (1) ponto às questões conformes e (0) para não conforme e cada centro recebeu um escore, de forma análoga a pontuação descrita acima, variando de acordo com o domínio. O escore máximo pontuado no 
questionário eletrônico com perguntas correlacionadas aos itens da IN4/ANVISA foi (Emax $=12$; I $\max =15$ e Pmax $=21$ ), sendo o escore total 48 pontos.

Para analisar o desempenho dos centros participantes da RNPC, em relação ao atendimento a requisitos de um SGQ, foi elaborado um índice de cumprimento para atendimento aos itens críticos e maiores, denominado ICCM (índice de conformidade com requisitos críticos e maiores), definido para cada domínio, como:

$$
\frac{\text { ICCM }=\text { Escore IN4 centro }}{\text { Escore IN4 máx x } 100}
$$

Os dados foram apresentados como mediana e valores mínimos e máximos. Foram consideradas significativas as diferenças que apresentaram $\mathrm{P}$ valor maior a 0,05 e testes bicaudais. Para a análise de correlação entre o questionário de $B P C$ e o desempenho na IN4/ANVISA foi usado o teste de Spearman. As comparações entre as variáveis de acordo com os domínios foram feitas por teste de Kruskall-Wallis, e quando pertinente, aplicado pós-teste de Dunn. As análises foram realizadas com o uso do programa Graphpad Prism v 6.0 (Graphpad software, Inc., La Jolla, CA, USA).

\section{RESULTADOS}

Dos 32 centros participantes da RNPC, 5 centros não responderam ao questionário, sendo um centro da região Nordeste e 4 centros da região Sudeste. Portanto, a coleta de dados foi concluída com um total de 27 questionários respondidos, o que representa $84 \%$ dos centros participantes da RNPC. Tabela 1

A Tabela 2 mostra a correspondência entre a classificação das observações no Guia de Inspeção em Boas Práticas Clínicas de acordo com a IN4/ANVISA e o questionário aplicado, o qual abrangeu aproximadamente $40 \%$ das questões dispostas no guia da IN4/ANVISA.

Tabela 1.

Centros que responderam ao questionário e regiões.

\begin{tabular}{lcrr}
\hline Região & Número de centros & \multicolumn{1}{c}{ Centros que responderam ao questionário } \\
\hline Centro-Oeste & 2 & No & $\%$ \\
Nordeste & 9 & 2 & 100 \\
Norte & 2 & 8 & 89 \\
Sudeste & 14 & 2 & 100 \\
Sul & 5 & 51 & 100 \\
\hline Total & 32 & 27 & 84 \\
\hline
\end{tabular}

Tabela 2.

\begin{tabular}{|c|c|c|}
\hline Classificação dos Itens & Questões IN4/ANVISA & Questionário Eletrônico \\
\hline C & 46 & 17 \\
\hline$M$ & 76 & 33 \\
\hline $\mathrm{Me}$ & 16 & 3 \\
\hline I NF & 13 & 7 \\
\hline Total & 151 & 60 \\
\hline
\end{tabular}

Relação itens IN4/ ANVISA e questionário eletrônico.

Classificação de não conformidades: Criticas (C), Maiores (M), Menores (Me) e Informativas (INF) - IN4/2009 - ANVISA. 
As perguntas dispostas no questionário eletrônico foram abordadas de forma geral, portanto, alguns itens da norma se repetiram na correlação com as perguntas do questionário. Também há perguntas do questionário que não correlaciona-se com os itens da IN № 4 - ANVISA. Além disso, a mesma pergunta do questionário eletrônico poderia ter relação com mais de um item da IN № 4 - ANVISA, mas para fim de pontuação, foi considerado apenas uma questão, sendo a de maior classificação na norma. A correlação entre questionário eletrônico e IN4/ANVISA e os resultados estão disponíveis no anexo 2 .

A figura 1 mostra a correlação entre o escore obtido com a aplicação do questionário com o escore observado pela aplicação da IN4/ANVISA.

A figura 2 mostra o desempenho dos centros participantes da RNPC, medido pelo índice de cumprimento para atendimento aos itens críticos e maiores, (ICCM), para cada domínio estudado. Não houve diferenças entre os valores de ICCM dos domínios estudados [E 70 (30-100); I 66,7 (33,3 - 91,7); P 73,3 (13,3-100); mediana $\min -\max , \% \mathrm{P}>0.05]$.

\section{DISCUSSÃO}

A coleta de dados foi concluída com um total de 27 questionários respondidos, o que representa $84 \%$ dos centros participantes da RNPC. Percentual considerado suficiente e satisfatório pelos pesquisadores, visto que, em média, os questionários enviados pelos pesquisadores alcançam $25 \%$ de devolução ${ }^{9}$. Esta taxa de resposta do questionário pode demonstrar o crescente interesse na área, o envolvimento dos centros e o compromisso em buscar atender o padrão de qualidade requerido para pesquisa clínica.

Os centros de pesquisa devem buscar a manutenção da qualidade de forma continua em todos os seus processos e desenvolver seu próprio SGQ para a execução de ensaios clínicos em BPC. Baseados nos conceitos, apresentados pela ABNT NBR ISO 9000:2005, pelo entendimento das diretrizes em pesquisa e pela experiência profissional em centros de pesquisa, concluiu-se que a estrutura organizacional, a infraestrutura e os processos de um centro de pesquisa, devem ser abordados de forma sistêmica, integrada, provendo atendimento a requisitos e resultando em um $\mathrm{SGQ}^{10}$.

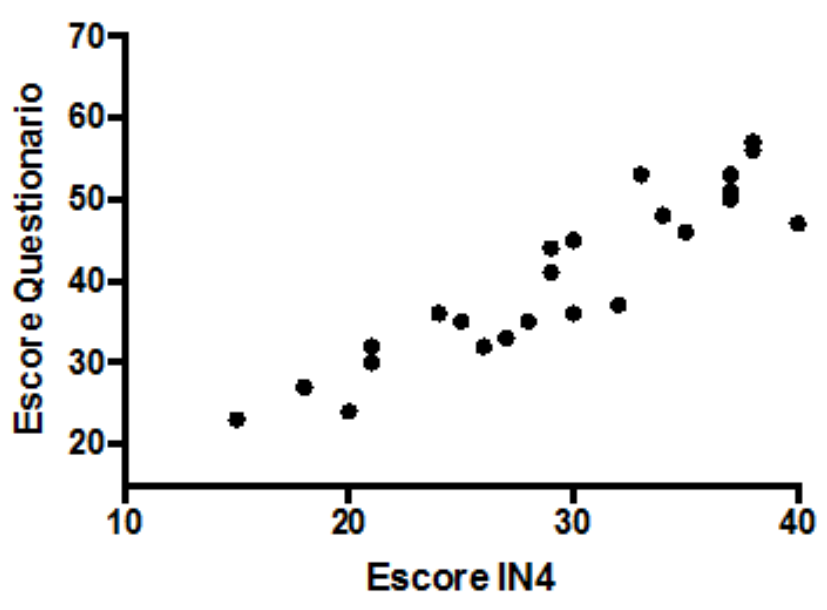

Figura 1: Correlação entre o escore questionário com o escore correspondente à IN4/ANVISA. Cada ponto representa um centro da RNPC estudado ( $r$ 0,95, 0,89-0,98; IC95\%, P<0,0001).

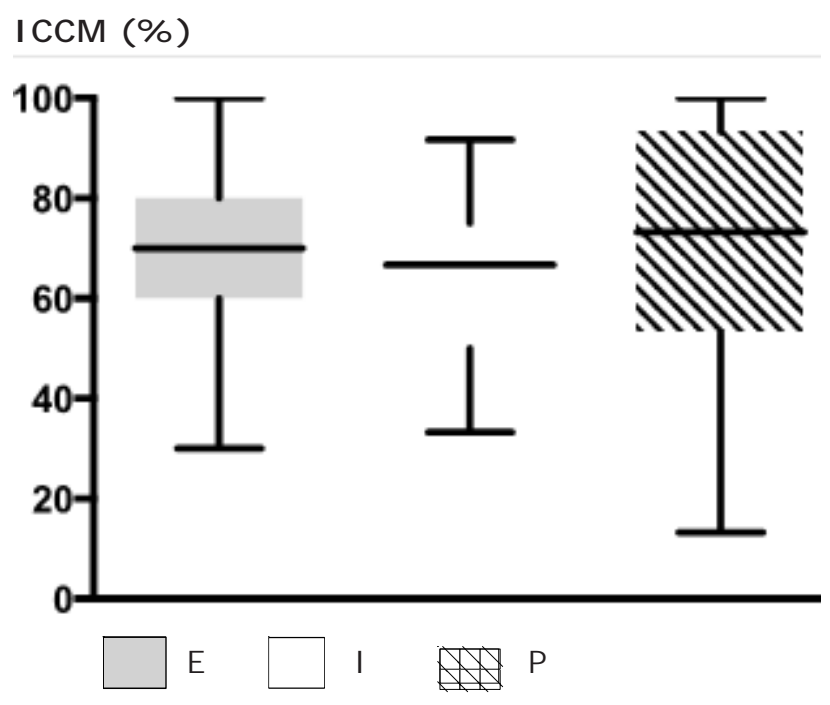

Figura 2: Box plot para a distribuição do índice de cumprimento para atendimento aos itens críticos e maiores (ICCM) de acordo com os domínios estudados ( $E=$ Estrutura, $I$ - infraestrutura e $P=$ processos). A barra representa a mediana e os intervalos os valores mínimos e máximos.

A falta de ferramentas adequadas para o diagnóstico do estado de desenvolvimento do SGQ em pesquisa clínica é um dos problemas para se evoluir na melhoria contínua dos centros. A utilização de um roteiro estruturado em auditorias internas, externas e inspeções auxilia o processo de avaliação do centro sobre as melhorias que devem ser implantadas e ressaltam que a avaliação da qualidade em centros de pesquisa 
contribui para o atendimento das diretrizes nacionais e internacionais, o que auxilia a manutenção da credibilidade do centro pela ótica de agências regulatórias, agências de fomento, patrocinadores e participantes de pesquisa ${ }^{11}$.

No presente trabalho, foi apresentado uma ferramenta útil para a avaliação crítica dos centros, com a possibilidade de detecção de problemas nos três domínios acima descritos. O questionário desenvolvido foi validado no ambiente de pesquisa clínica nacional e reflete, desta forma, as dificuldades e particularidades de execução de ensaios clínicos em Hospital Públicos de Ensino. Ainda, a figura 1 mostra que existe uma forte correlação entre o desempenho no questionário para BPC com os itens inspecionados pela ANVISA e descritos na IN4. Portanto, o instrumento desenvolvido para medir o desempenho em BPC pode ser utilizado para auditoria interna de qualidade pelos centros de pesquisa clínica nacionais.

Foi observado uma alta variabilidade nos escores de qualidade, com poucos centros próximos de atender a plenitude das exigências da ANVISA. Nenhum centro brasileiro pertencente a RNPC conseguiu ter o ICCM em $100 \%$, cenário ideal em uma inspeção. Ainda, a mediana do ICCM ficou abaixo de $75 \%$, o que sugere que as exigências regulatórias atuais são rigorosas demais e necessitam ser adequadas ao cenário nacional de forma a possibilitar a evolução da pesquisa clínica em Hospitais Públicos.

$O$ instrumento ainda permitiu avaliar três domínios relevantes para um SGQ: estrutura organizacional, infraestrutura e processos (figura 2). Como pode ser observado, nenhum dos domínios se mostrou mais crítico que os outros. A gestão de processos em pesquisa clínica é complexa e carece de bons instrumentos para sua condução. Entretanto, este domínio depende diretamente da gestão do centro de pesquisa e sofre uma menor influência da direção do Hospital Escola, quando comparado a infraestrutura e a estrutura organizacional. A falha neste domínio alerta aos centros de pesquisa da RNPC que ações conjuntas podem ser tomadas para sanar tais problemas.

Cabe ressaltar no contexto de "qualidade em saúde" que este não é um conceito rígido e é considerado de certa forma complexo ${ }^{12}$. A corren- te predominante de pensamento nesta área é centrada na busca da qualidade total ${ }^{13}$. Neste conceito, de acordo com Oliveira e cols (2009) ${ }^{14}$ o foco está centrado no cliente, e, portanto, as organizações em saúde buscam satisfazer as expectativas e necessidades destes, na maioria dos casos, usuários dos sistemas de saúde. Dentro deste conceito, alguns autores como Burmester (2013) ${ }^{15}$ advogam que toda a instituição deve estar empenhada na manutenção da qualidade e não um determinado setor ou profissional, como um gerente da qualidade. Segundo o autor, corre-se o risco de que os demais membros da instituição se ausentem da responsabilidade em manter a qualidade, já que esta é atribuída a um setor ou para algum profissional. Entretanto, para pesquisa clínica, existem múltiplos clientes com necessidades distintas. Participantes de pesquisa clínica têm a expectativa de resolução de seus problemas de saúde com alguma nova abordagem terapêutica, patrocinadores esperam que os centros atendam as BPC, pesquisadores buscam agilidade na execução de seus protocolos e a instituição proponente zela por sua imagem de centro inovador. Este cenário torna a pesquisa clínica mais complexa ainda que a área de saúde e a figura de um gestor de qualidade se torna crítica. Nas respostas de nossos questionários observamos que a minoria dos Centros da RNPC tem um profissional dedicado à qualidade. Ao considerarmos os 27 centros participantes da RNPC que responderam ao questionário, apenas $14,8 \%$ contam com a presença de um gerente de qualidade com dedicação exclusiva para as atividades de pesquisa clínica.

Como medida para o desenvolvimento dos centros de pesquisa participantes da RNPC a Coordenação Geral de Pesquisa Clínica (CGPC), o Departamento de Ciência e Tecnologia (DECIT)/ MS, tem promovido competências para a atuação profissional, no desenvolvimento de projetos de pesquisas e na gestão de centros de pesquisas, por meio do Programa de Apoio ao Desenvolvimento Institucional do Sistema Único de Saúde ${ }^{16}$.

Embora todo este incentivo em capacitação de recursos humanos, a melhoria da infraestrutura e da estrutura organizacional dependem diretamente do investimento dos Hospitais de Ensino ou das agências de fomento. Os Hospitais 
de ensino, particularmente os federais, tem passado por um processo de reforma de gestão por meio da Empresa Brasileira de Serviços Hospitalares (EBSERH), que tem por finalidade a prestação de serviços gratuitos de assistência médicohospitalar, ambulatorial e de apoio diagnóstico e terapêutico à comunidade, assim como a prestação às instituições públicas federais de ensino ou instituições congêneres de serviços de apoio ao ensino, à pesquisa e à extensão, ao ensinoaprendizagem e à formação de pessoas no campo da saúde pública ${ }^{17}$.

Os centros de pesquisa têm que disputar, neste cenário, verbas e investimentos com o SUS, sendo claramente preteridos, uma vez que a prioridade dos gestores hospitalares é a de sanar problemas com a assistência médica. Nos últimos anos, um número crescente de editais abertos pelo DECIT em pareceria com o Conselho Nacional de Desenvolvimento Científico e Tecnológico (CNPq) e a Financiadora de Estudos e Projetos (FINEP) tem incentivado a realização de projetos de pesquisa multicêntricos, por meio do Programa Pesquisa para o SUS: gestão compartilhada em Saúde - PPSUS ${ }^{18}$.

O PPSUS tem como objetivo financiar pesquisas em temas prioritários para a saúde da população brasileira, contribuir com o aprimoramento SUS e promover o desenvolvimento científico e tecnológico em saúde em todos os estados da federação ${ }^{18}$.

Entretanto, tais alíneas são muitas vezes direcionadas a execução dos projetos, ficando os investimentos nos centros de pesquisa em segundo plano. O DECIT/MS abriu a sua última chamada para a estruturação de centros de pesquisa em 2005, ou seja, há mais de uma década. Sem investimentos continuados neste setor será difícil observar as melhorias de infraestrutura exigidas pela IN4/ANVISA. Cria-se um cenário paradoxal em que o órgão governamental regulador aponta falhas nos centros de pesquisa públicos, sem acenar para possíveis soluções, o que impede que o setor se desenvolva. Desta forma é urgente que alíneas de investimento para a estruturação e melhoria continuada dos centros de pesquisa sejam criadas e mantidas.

Foi considerado ainda, como medida factível com a realidade dos centros de pesquisa clínica no Brasil, que sejam seguidos um conjunto de procedimentos mínimos que atendam aos critérios de consistência dos dados, aderência ao protocolo e sobretudo, a segurança e bem-estar dos participantes de pesquisa. Assim, muitos dos pontos avaliados como críticos ou maiores, passariam para oportunidades de melhoria. O trabalho de inspeção poderia ter uma abordagem mais educativa que restritiva e o diagnóstico dos problemas comuns aos centros da RNPC debatidos e sanados pelo seu gestor, o DECIT /MS. Conceitos como o aperfeiçoamento contínuo em qualidade 19 baseados em PDCA ( $P$ : planning; D: do; C: control; A: Action) podem ser implantados como melhoria dos processos para a garantia da manutenção da qualidade.

Como limitações para a realização deste estudo, destaca-se a impossibilidade de verificar localmente se as respostas obtidas dos centros de pesquisa refletem a realidade e que não foi possível abordar todos os itens da IN4/ANVISA.

As perguntas dispostas no questionário eletrônico foram abordadas de forma geral, portanto, alguns itens da norma se repetiram na correlação com as perguntas do questionário, mas para fim de pontuação, foi considerado apenas uma questão, sendo a de maior classificação na norma. Também há perguntas do questionário que não correlaciona-se com os itens da IN4/ANVISA.

Outra limitação foi a diversidade de perfis profissionais que responderam ao questionário. Embora inicialmente a solicitação para preenchimento tenha sido enviada ao coordenador do centro de pesquisa, sabendo que esta restrição poderia dificultar a coleta de dados, foi informado que outro funcionário do centro de pesquisa poderia responder, o que de alguma forma, pode causar um viés de preenchimento.

Em conclusão, o presente estudo desenvolveu e validou um questionário de avaliação de desempenho em BPC que pode ser utilizado como ferramenta de diagnóstico simples para predizer o desempenho de um centro de pesquisa frente a inspeções da ANVISA. Os dados revelam que os centros da RNPC apresentam um grau variável de amadurecimento do SGQ em pesquisa clínica e que os centros não atingiram $75 \%$ de atendimento aos itens da IN № 4 - ANVISA, considerando itens críticos e maiores. O estudo mostra 
que os centros pertencentes a RNPC necessitam fortalecer suas ações, particularmente no domínio dos processos e da estrutura organizacional, visando a consolidação de SGQ. Investimento continuado do setor público e privado em infraestrutura e recursos humanos nos centros de pesquisa da RNPC pode auxiliar a transpor tais dificuldades, preparando o país para um cenário favorável para o desenvolvimento de novos medicamentos, vacinas e testes diagnósticos, visto que, a pesquisa clínica é o elo da ciência com o setor produtivo.

\section{REFERÊNCIAS}

1. Agência Nacional de Vigilância Sanitária (BR), Medicamentos. Pesquisa Clínica. Brasília, DF, 2010.

2. Karlberg JPE, Speers MA. Revisão de estudos clínicos: um guia para o comitê de ética. Hong Kong: 2010. 153 p.

3. International Conference on Harmonization of technical requirements for the registration of pharmaceuticals or human use - ICH. Harmonised tripartite guideline for good clinical practice. Richmond: Brookwood Medical Publicacion, 1996.

4. Integrity Research. 5 big things to know about ICH E6 (R2). mar2017. Disponível em:<https:// integrityresearch.ca/ich-e6-r2/.>. Acesso em: 21 jan. 2018.

5. Rede Nacional de Pesquisa Clínica do Brasil: respostas e redução da dependência estrangeira. Rev. Saúde Pública. 2010; 44(3): 575-578. DOI: 10.1590/S0034-89102010000300024.

6. Lousana G. Pesquisa clínica: fluxos regulatórios no Brasil. 1. ed. Rio de Janeiro: Revinter; 2013.

7. Agência Nacional de Vigilância Sanitária (BR), Instrução normativa no 4, de 11 de maio de 2009 . Dispõe sobre o Guia de Inspeção em Boas Práticas Clínicas. Brasília, DF, 2009.

8. Polit, DF, Beck CT, The content validity index: Are you sure you know what's being reported? critique and recommendations. Res. Nurs. Health, 2016; 29: 489-497. DOI: 10.1002/nur. 20147
9. Marconi MDA, Lakatos EM. Técnicas de pesquisa: planejamento e execução de pesquisas, amostragens e técnicas de pesquisas, elaboração, análise e interpretação de dados. 7.ed. São Paulo: Atlas, 2008

10. Associação Brasileira de Normas Técnicas (BR), NBR ISO 9000: Sistemas de Gestão da Qualidade, fundamentos e vocabulário. Rio de Janeiro, 2005

11. Lima KS, Vidal BB, Lage APD, Wainstein AJA. Análise crítica da qualidade dos centros de pesquisa clínica de Belo Horizonte. Cienc. Cult. 2014; 66(1): 34- 37 .

12. Bonato. VL. Gestão de qualidade em saúde: meIhorando assistência ao cliente. O Mundo da Saúde, São Paulo: 2011;35(5):319-331.

13. MOURA, L. R. Qualidade simplesmente total: uma abordagem simples e prática da gestão da qualidade. Rio de Janeiro: Qualitymark, 1997.

14. Oliveira, OJ et al. Gestão da qualidade - Tópicos avançados, 2009

15. BURMESTER, Haino. Gestão da qualidade hospitalar. Revista da Faculdade de Ciências Médicas de Sorocaba, [S.I.], v. 15, n. 3, p. 73-75, set. 2013. ISSN 1984-4840. Disponível em:<https:// revistas.pucsp.br/index.php/RFCMS/article/view/ 16523>. Acesso em: 07 mar. 2018.

16. Brasil. Portal da Saúde. PROADI-SUS - Programa de Apoio ao Desenvolvimento Institucional do Sistema Único de Saúde. 2014.

17. Brasil. Decreto n. 12.550, de 15 de dezembro de 2011. Autoriza o poder executivo a criar a empresa pública denominada Empresa Brasileira de Serviços Hospitalares - EBSERH. 1900 da Independência e 1230 da República. Brasília, DF, 2011.

18. Ministério da Saúde (BR), Secretaria de Ciência, Tecnologia e Insumos Estratégicos. Departamento de Ciência e Tecnologia. Programa Pesquisa para o SUS: gestão compartilhada em saúde: diretrizes técnicas/ Ministério da Saúde, Secretaria de Ciência, Tecnologia e Insumos Estratégicos, Departamento de Ciência e Tecnologia. 4. ed. Brasília, DF, 2011.

19. DEMING, W. E. Quality, productivity and competitive position. Boston: MIT Press, 1982. 


\section{ANEXO 1}

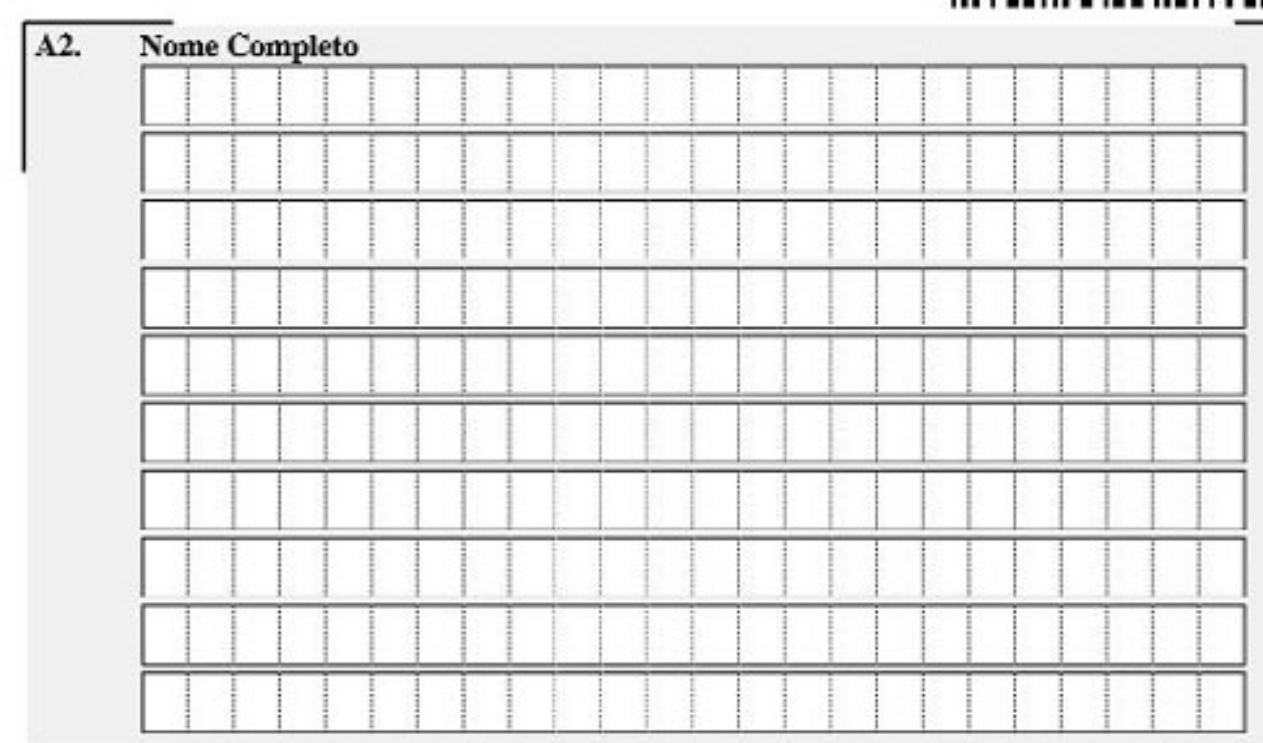

A3. Data

\section{Section B: Informaç̃es de Contato}

B1. Dados do responsável pelo preenchimento deste questionário

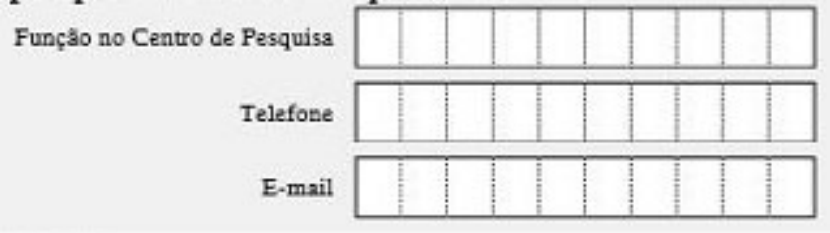

\section{B2. Dados do Centro de Pesquisa}

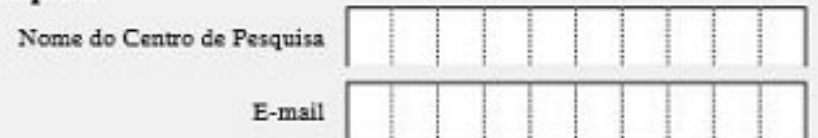

B3. O centro de pesquisa é administrado por:

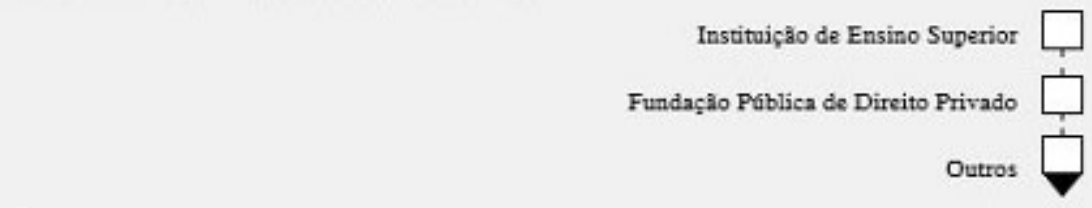

Outros 


\section{ANEXO 1}

\section{Section C: Processo Regulatório}

\section{||||||||||||||||||||||||}

C1. Após a implantaçāo da Plataforma Brasil, a submissāo de novos projetos ao CEP é realizada:

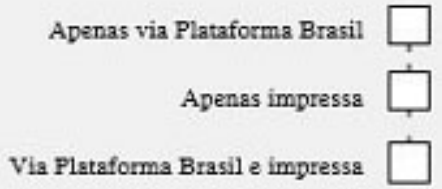

C2. A instituiçāo exige que o protocolo seja avaliado por alguma comissāo interna além do Comitê de Ética?

Nāo

Sim, anslise de orçamento

Sim, analise do departamento onde a pesquisa ser realizada

Outros

Outros

\section{Section D: Recursos Humanos}

D1. A Instituiçāo possui funcionários com dedicação exclusiva para as atividades de Pesquisa Clínica?

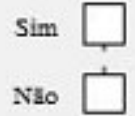




\section{ANEXO 1}

D2. Por favor relacione abaixo a quantidade de profissionais com dedicaçāo exclusiva para as atividades no centro de pesquisa.

Caso nāo haja este perfil de profissional, completar com o numeral 0.

Se houver profissionais que nāo estāo listados abaixo, por favor, inserir na opção outros a função e a quantidade.

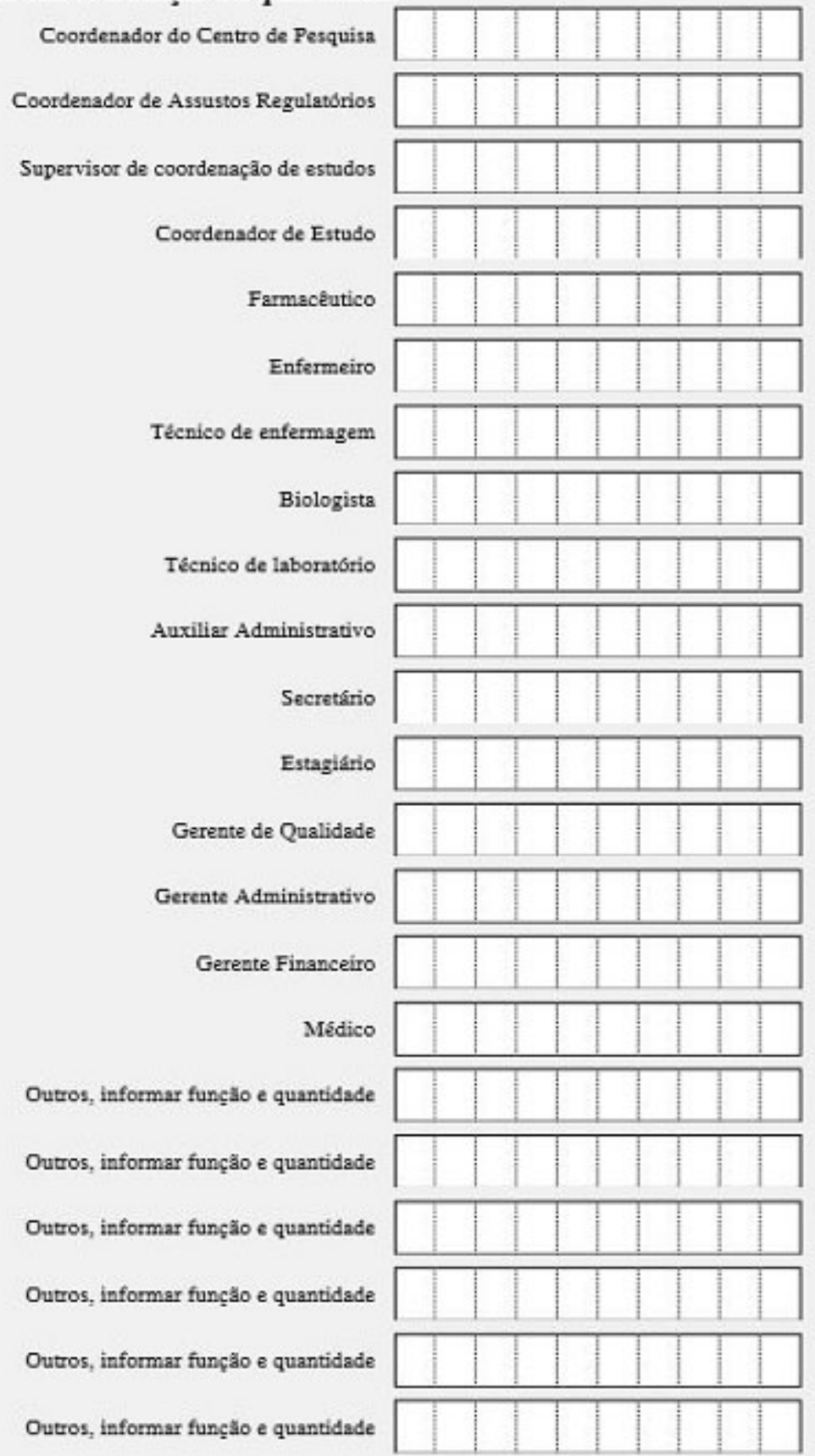




\section{ANEXO 1}

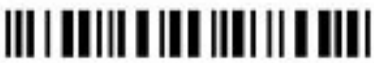

\section{Section E: Infraestrutura e Estrutura Oganizacional}

E1. O centro possui uma farmácia exclusiva para pesquisa clínica?

$$
\text { Nåo, o produto investigacional } 6 \text { armazenado na farmácia da Instituiçăo }
$$

Năo, o produto investigacional 6 armazenado na sala de coordenaçalo de estudos

Năo, o produto investigacional 6 amazenado na sala do investigador principal

$\mathrm{Na}$, o produto investigacional $\varepsilon$ amazenado no ambulatorio de atendimento

Outros

Outros

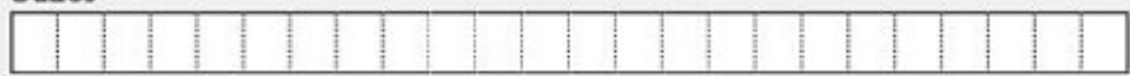

E2. Existe controle de temperatura no local onde o produto investigacional é armazenado?

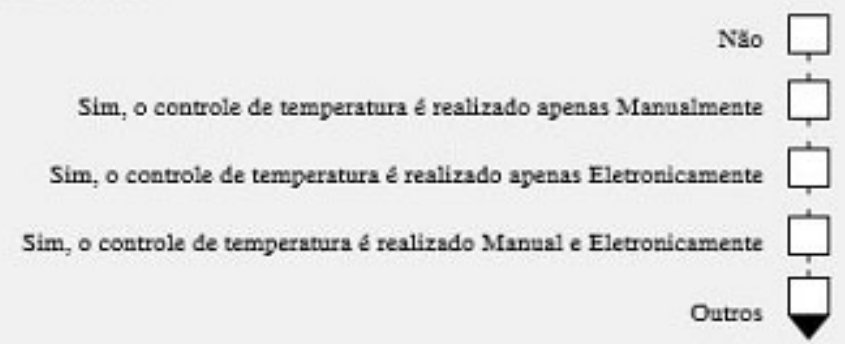

Outros

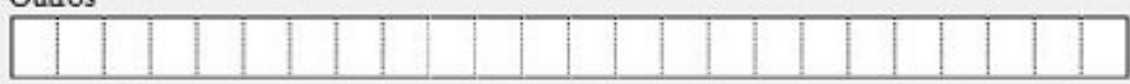

E3. O local onde o produto investigacional é armazenado possui acesso restrito?

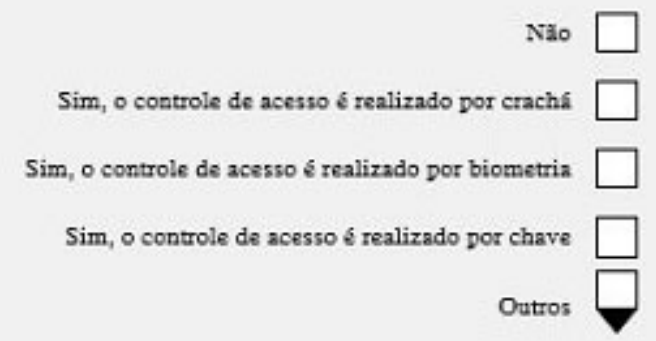

Outros

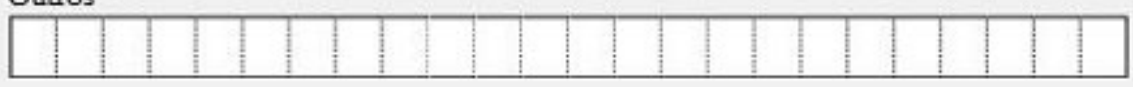




\section{ANEXO 1}

E4. O centro possui Laboratório específico para pesquisa clínica?

$$
\text { Nāo, as amostras dos estudos sắo processadas e armazenadas no laboratório da Instituição }
$$

Não, as amostras dos estudos sîo processadas e armazenadas em laboratorio particular contratado

Outros

Outros

\begin{tabular}{|l|l|l|l|l|l|l|l|l|l|l|l|l|l|l|l|l|}
\hline & & & & & & & & & & & & & & & & \\
\hline
\end{tabular}

E5. Existe controle de temperatura no local de armazenamento das amostras de pesquisa clínica?

Nลัง

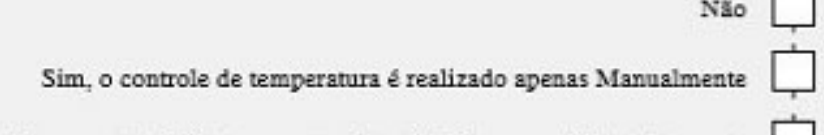

Sim, o controle de temperatura $\varepsilon$ realizado apenas Eletronicamente

Sim, o controle de temperatura e realizado Manual e Eletronicamente

Outros

Outros

\begin{tabular}{|l|l|l|l|l|l|l|l|l|l|l|l|l|l|l|l|}
\hline & & & & & & & & & & & & & & & \\
\hline
\end{tabular}

E6. O local onde as amostras dos estudos sāo processadas e armazenadas possui acesso restrito?

Nă๋

Sim, o controle de acesso $s$ realizado por crachá

Sim, o controle de acesso $\delta$ realizado por biometria

Sim, o controle de acesso é realizado por chave

Outros

Outros

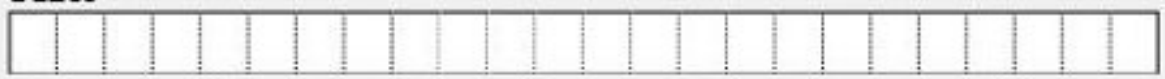

E7. O centro de pesquisa possui consultórios específicos para atendimento aos participantes de pesquisa clínica?

$\operatorname{sim}$

Năo, os atendimentos såo realizados em ambulat6rio e/ou enfermaria da propria Instituiçăo

NIIo, os atendimentos salo realizados em ambulatorio e/ou enfermaria de instituiçlo particular contratada

Outros

Outros

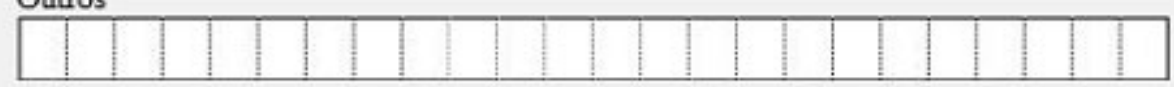




\section{ANEXO 1}

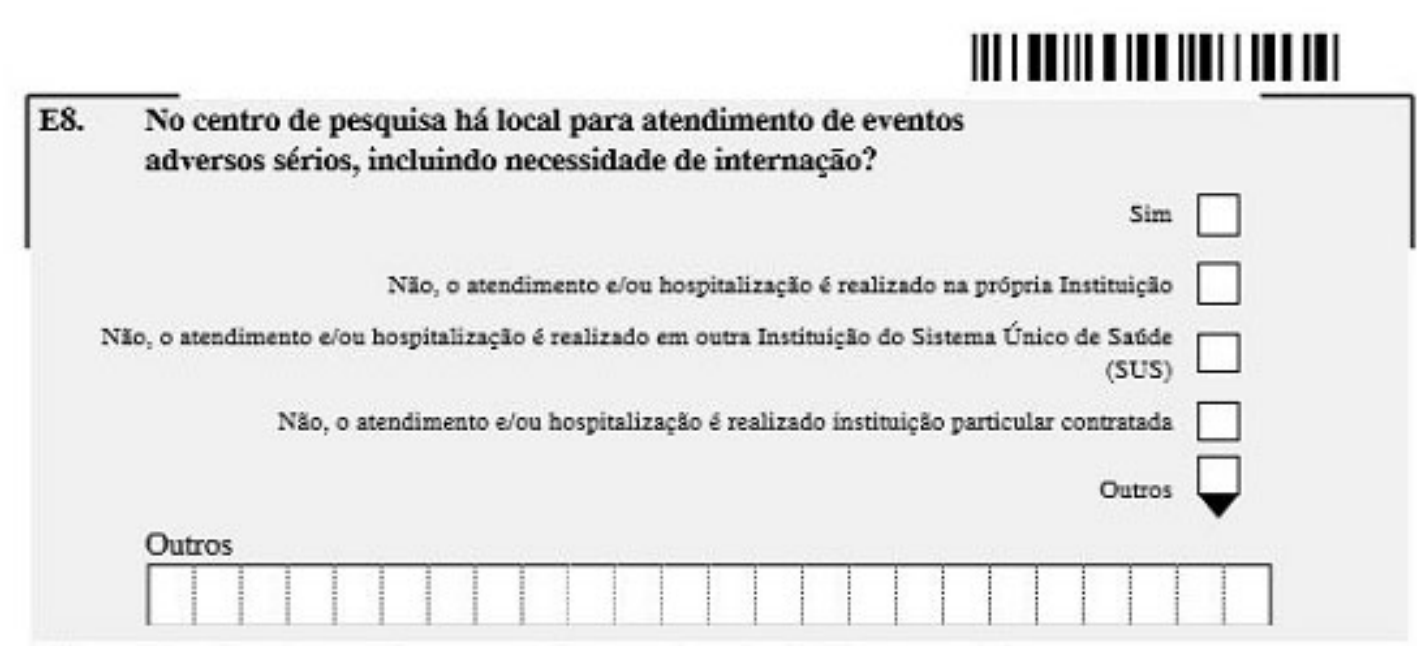

E9. O centro de pesquisa possú infraestrutura de UTI localmente?

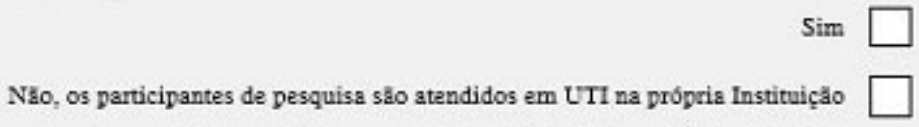

Nå, os participantes de pesquisa săo atendidos em UTI em outra Instituiçâa do Sistema Único de Saúde

(SUS)

Nio, os participantes de pesquisa sio atendidos em UTI de instituiçio particular contratada

Outros

Outros

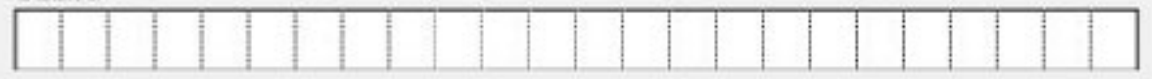

E10. O centro possui local exclusivo para arquivo dos documentos dos estudos clínicos em andamento?

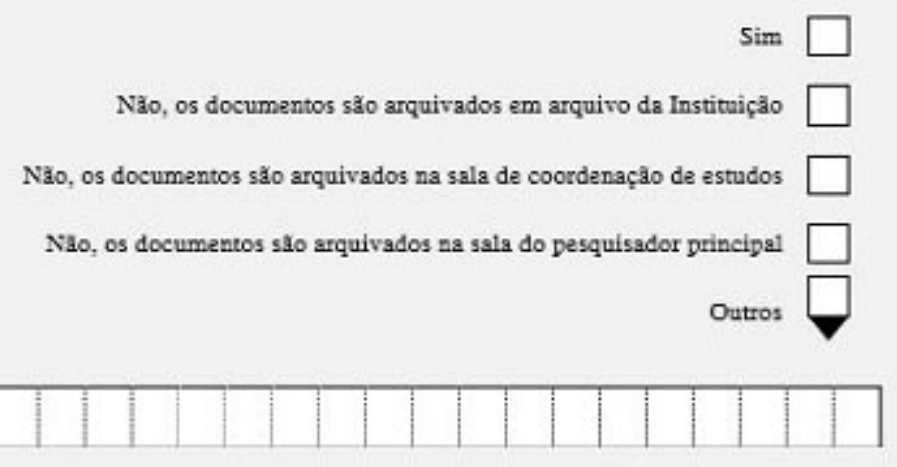

Outros

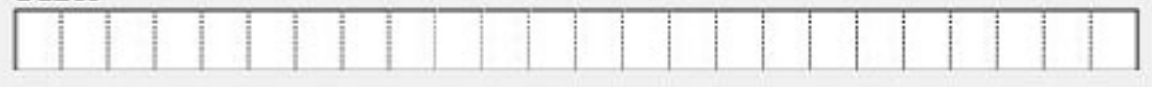




\section{ANEXO 1}

E11. O arquivo de pesquisa clínica possui acesso restrito?

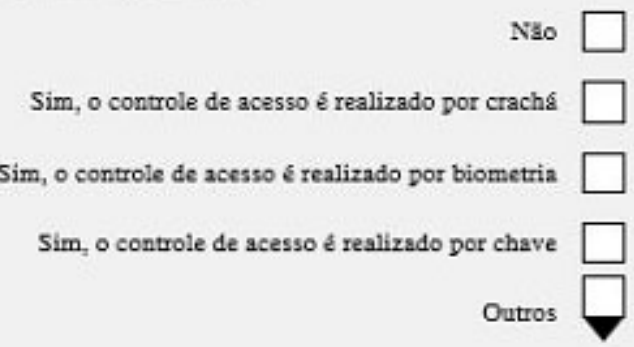

Outros

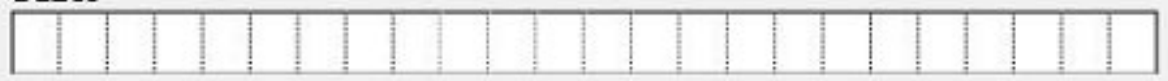

E12. Referente ao arquivo, por favor, marque as opç̃es aplicáveis ao centro de pesquisa:

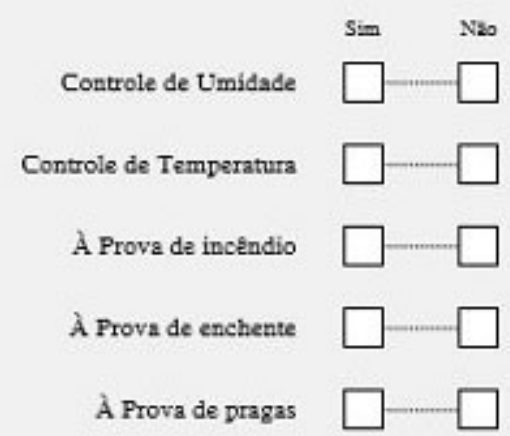

E13. Após o fim do estudo, onde os documentos sāo arquivados?

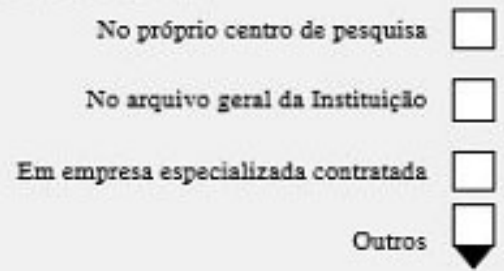

Outros

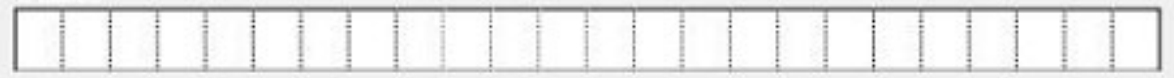

E14. Referente ao prontuário utilizado no centro de pesquisa:

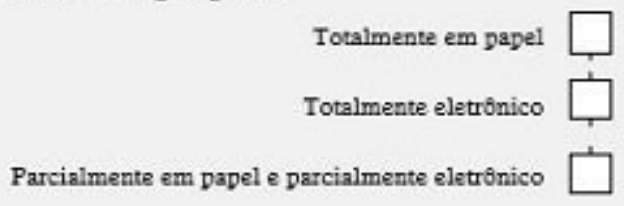




\section{ANEXO 1}

E15. Sendo o prontuário eletrônico, atende aos requisidos do CFR

(Code Federal Regulation) part 21 - Food and Drug

Administration (FDA) guidelines on electronic records and

electronic signatures?

\section{||||||||||||||||||||||||||}

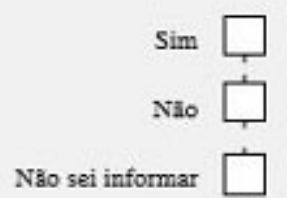

E16. O centro de pesquisa possuí um sistema eletrônico especifico para gerenciamento dos projetos de pesquisa?

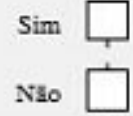

E17. Qual o número aproximado de protocolos em andamento no centro de pesquisa?

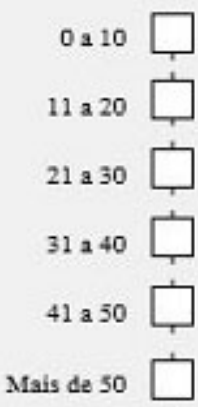

E18. Qual o número aproximado de protocolos finalizados no centro de pesquisa?

Mais de 50




\section{ANEXO 1}

E19. Qual o número aproximado de protocolos em feasibility centro de pesquisa?

Mais de $25 \square$

\section{Section F: Sistema de Gestão e Garantia da Qualidade}

F1. O centro de pesquisa possui um sistema de gestāo de qualidade?

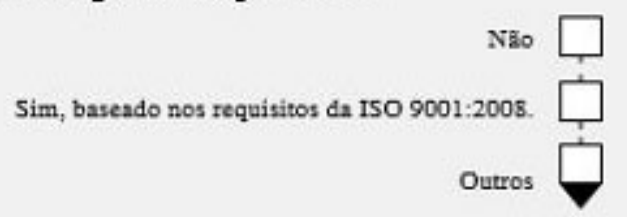

Outros

\begin{tabular}{|l|l|l|l|l|l|l|l|l|l|l|l|l|l|l|l|l|l|}
\hline & & & & & & & & & & & & & & & & & \\
\hline
\end{tabular}

F2. O sistema de gestāo da qualidade é certificado?

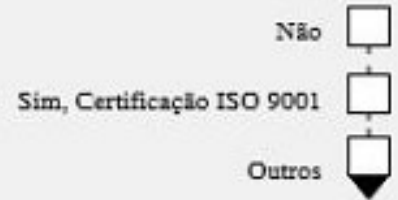

Outros

\begin{tabular}{|l|l|l|l|l|l|l|l|l|l|l|l|}
\hline 1 & Outros \\
\hline 1 & |
\end{tabular}

F3. O Centro de Pesquisa possui:

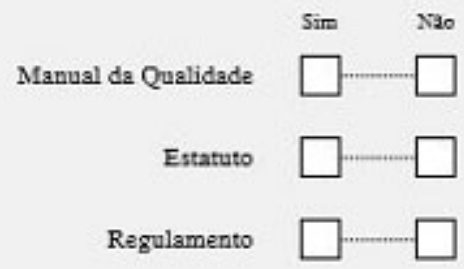




\section{ANEXO 1}

F4. Por favor, aponte a experiência do centro de pesquisa em auditorias e/ou inspeçāo?

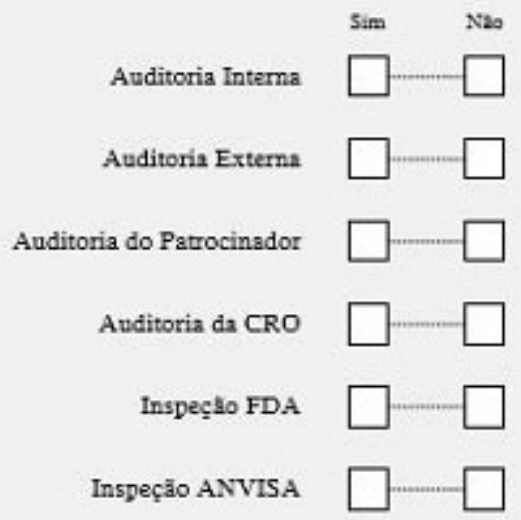

F5. O Laboratório de Patologia Clínica, onde sāo realizados os exames de pesquisa clínica é certificado?

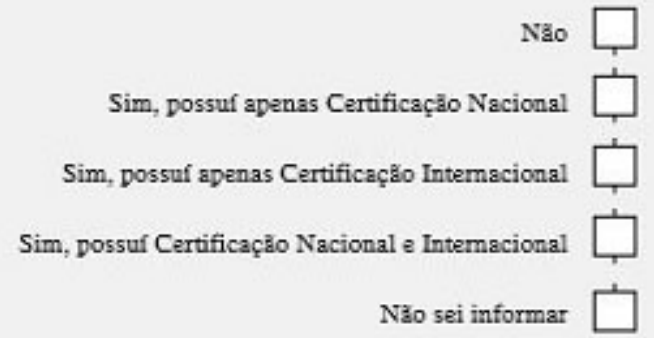

F6. Os funcionários do Centro de Pesquisa possuem treinamento em Boas Práticas Clínicas?

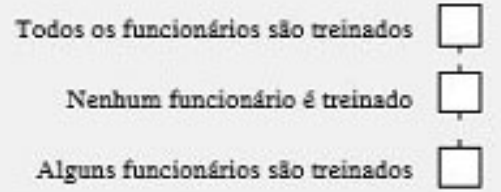

F7. O centro de pesquisa possui os Procedimentos Operacionais Padrāo (POP) requeridos na INSTRUÇÃO NORMATIVA N ${ }^{\circ}$, DE 11/05/09 - ANVISA, que Dispóe sobre o Guia de Inspeçāo em Boas Práticas Clínicas?

$$
\begin{aligned}
& \text { Sim, o centro de pesquisa possuf todos os POPs requeridos } \\
& \text { Näo, o centro de pesquisa não possur nenhum POP requerido } \\
& \text { O centro de pesquisa possuf alguns dos POPs requeridos } \\
& \text { Näo sei informar }
\end{aligned}
$$

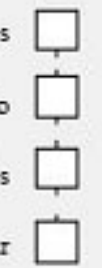




\section{ANEXO 1}

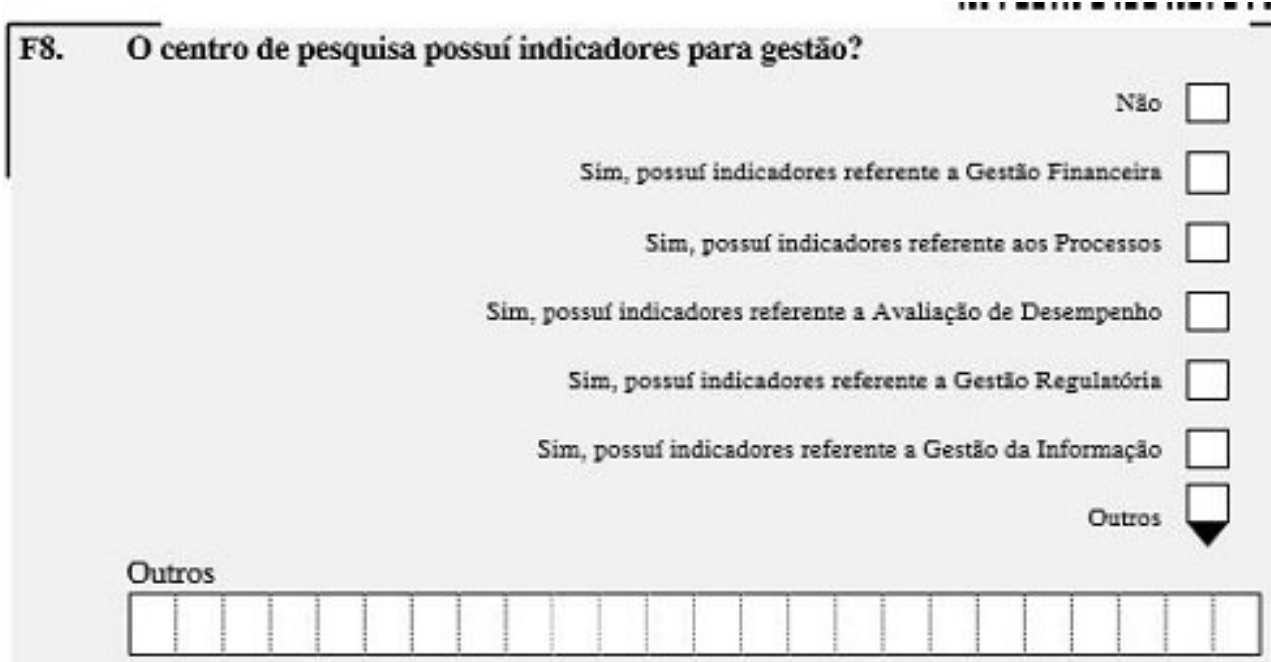




\section{ANEXO 1}

F9. O Centro de Pesquisa possui procedimento operacional, plano estratégico, plano gerencial ou processo que contemple:

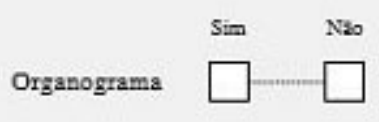

Descriçalo das responsabilidades $e$ autoridades dos cargos chave

Procedimentos que garantem a confidencialidade da informaçào

Procedimentos que garantem a confiabilidade dos resultados

Procedimentos que garantem ao cumprimento de normas e leis aplicáveis

Implementaçio e revislo dos Procedimentos Operacionais

Plano de Competéncia Pessoal

Plano de atividades perídicas

Sistemática definida para comunicaçĩo interna

Sistemática para Treinamento da equipe

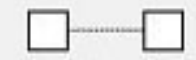

Treinamento em Boas Práticas Clínicas

Treinamento nos Procedimentos Operacionais

Treinamento nas diretrizes, normativas e regulamentaç6es em pesquisa clínica

Plano para tratamento de reclamaçóes de clientes
Controle de documentos físicos
Controle de documentos eletronicos

Plano para tratamento de reclamaçóes de clientes
Controle de documentos físicos
Controle de documentos eletronicos
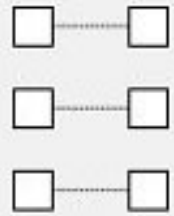

Controle de documentos eletronicos

Sistemática para realizaç̌lo de copias de segurança (backup) de toda a documentaça eletronica

Plano de controle de periodicidade de calibraçăo dos equipamentos

Monitoramento de desempenho do estudo, por exemplo, acompanhamento das taxas de recrutamento, taxas de inclusăo e falhas de inclusåo.

Relatório de nå̃o conformidade
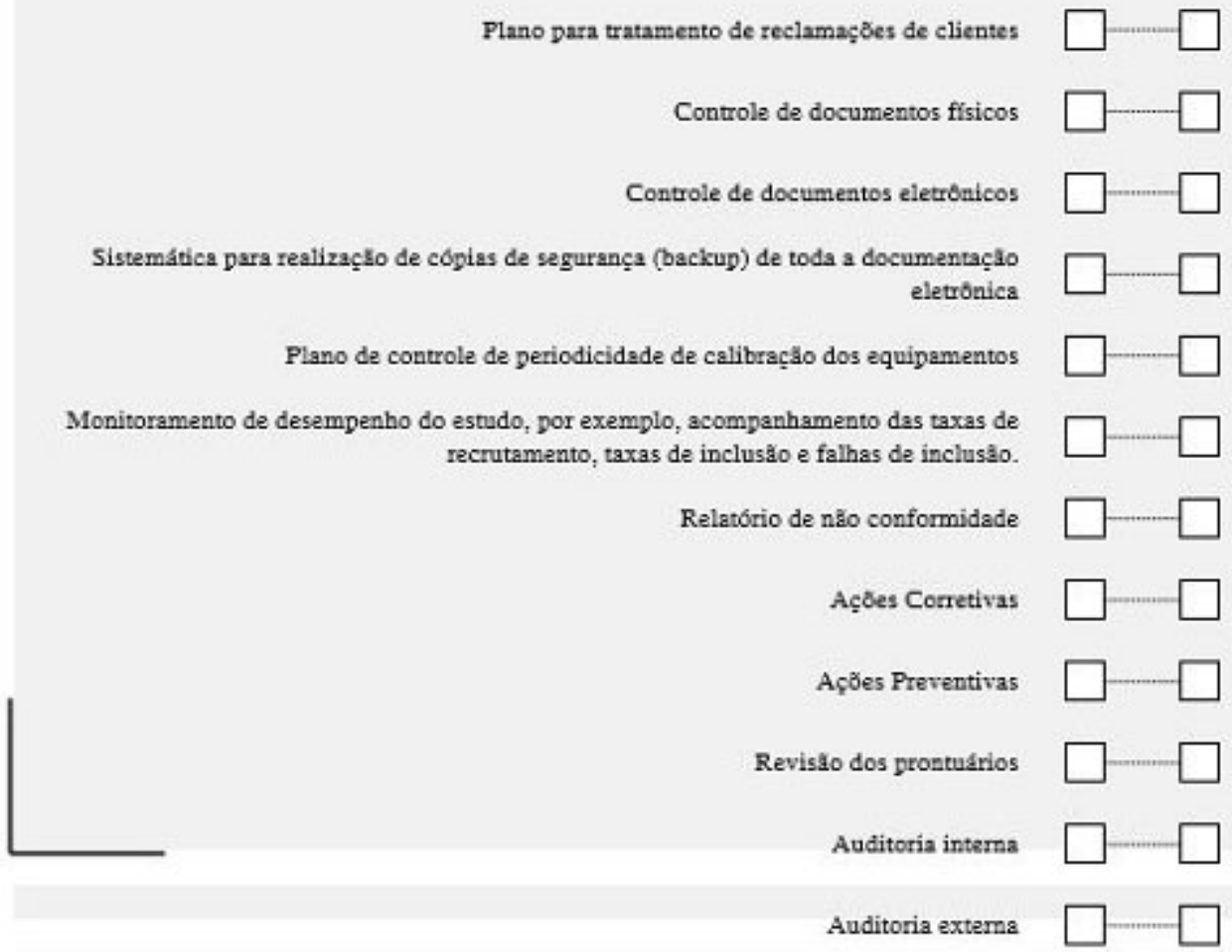


\section{ANEXO 2}

\begin{tabular}{|c|c|c|c|c|}
\hline \multicolumn{5}{|c|}{ Domínio - Estrutura Organizacional (E) } \\
\hline $\begin{array}{l}\text { № Questão no } \\
\text { Questionário }\end{array}$ & $\begin{array}{l}\text { Objetivo da Pergunta } \\
\qquad(E \max =21)\end{array}$ & $\begin{array}{c}\text { Correlação com } \\
\text { a IN4/ANVISA } \\
\text { (S/N) } \\
\text { (Emax= 12) }\end{array}$ & $\begin{array}{l}\text { Item e Classificaxảo } \\
\text { descritos no Roteiro de } \\
\text { Inspeção da IN4/ANVISA }\end{array}$ & Frequência (\%) \\
\hline 9 & $\begin{array}{c}\text { Funcionários com dedicação } \\
\text { exclusiva para as atividades de } \\
\text { Pesquisa Clínica }\end{array}$ & N & Näo Applicável & $78 \%(\mathrm{Sim})$ \\
\hline
\end{tabular}

Dos 21 centros que responderam que contavam com profissionais com dedicação exclusiva para as atividades de Pesquisa Clínica na Instituiçào, há pelo menos 1 dos funcionários abaiko listados:

\begin{tabular}{|c|c|c|c|c|}
\hline \multirow{6}{*}{10} & Enfermeiro & 5 & A 3.3 (Malor) & $9586(5 \mathrm{im})$ \\
\hline & Técnico de Enfermagom & $\mathrm{N}$ & Näo Aplicável & $52 \%(\mathrm{Sim})$ \\
\hline & Farmacêutico & $s$ & A.4.3 (Maior) & $76 \%(\mathrm{Sim})$ \\
\hline & $\begin{array}{c}\text { Coordenador de Assuntos } \\
\text { Regulatórios }\end{array}$ & s & A.7.3 (Maior) & $38 \%(5 \mathrm{im})$ \\
\hline & Gerente de Qualidade & $s$ & B. 3 (informativa) & $19 \%(\mathrm{Sim})$ \\
\hline & Coordenador de Estudo & $\mathrm{N}$ & Näo Aplicável & $76 \%(\mathrm{Sim})$ \\
\hline \multicolumn{5}{|c|}{ Experiência do centro de pesquisa em auditorias e/ou inspestä } \\
\hline \multirow{6}{*}{33} & Auditoria Interna & $\mathrm{N}$ & N5̈o Aplicável & $56 \%(\mathrm{Sim})$ \\
\hline & Auditoria Externa & $\mathbb{N}$ & Não Aplicável & $67 \%(\mathrm{sim})$ \\
\hline & Auditoria do Patrocinador & $\mathrm{N}$ & N3̈o Aplicável & $748(5 \mathrm{im})$ \\
\hline & Auditoria da CRO & $\mathrm{N}$ & Näo Aplicável & $67 \%(\mathrm{Sim})$ \\
\hline & Inspeção FDA & $\bar{N}$ & Não Aplicável & $11 \%(5 \mathrm{im})$ \\
\hline & Inspeção ANVISA & $\mathrm{N}$ & Nào Aplicãvel & $33 \%(5 \mathrm{im})$ \\
\hline 35 & $\begin{array}{c}\text { Todos os funcionários do Centro de } \\
\text { Pesquisa possuem treinamento em } \\
\text { Boas Práticas Clinicas? }\end{array}$ & s & B. 8 (Maior) & $85 \%(5 \mathrm{im})$ \\
\hline \multicolumn{5}{|c|}{ \$6 de centros que possuem procedimento operacional, plano estratégico, plano gerencial ou processo: } \\
\hline \multirow{7}{*}{38} & Organograma & 5 & S.1 (Menor) & $70 \%(5 i m)$ \\
\hline & $\begin{array}{c}\text { Descriçào das responsabilidades e } \\
\text { autoridades dos cargos chave }\end{array}$ & s & $\begin{array}{c}\text { A.7.3 (Maior); B.11 (Maior) } \\
; \text { C.2.1.22 (Critica) }\end{array}$ & $74 \%(5 \mathrm{im})$ \\
\hline & Plano de Competêncla Pesscal & s & A.7.3 (Malor) & $26 \%(5 \mathrm{im})$ \\
\hline & $\begin{array}{c}\text { Sistemática para Treinamento da } \\
\text { equipe }\end{array}$ & S & $\begin{array}{c}\text { A.4.4 (Critica); } 8.8 \text { (Maior); } \\
\text { C.1.2.1 (Maior) }\end{array}$ & $67 \%(\operatorname{Sim})$ \\
\hline & $\begin{array}{l}\text { Treinamento em Boas Práticas } \\
\text { Clinicas }\end{array}$ & 5 & $\begin{array}{c}\text { A.4.4 (Critica); } 8.8 \text { (Maior); } \\
\text { C.1.1.18 (Maior) }\end{array}$ & $96 \%(5 \mathrm{im})$ \\
\hline & $\begin{array}{c}\text { Treinamento nos Procedimentos } \\
\text { Operacionais }\end{array}$ & $\mathbf{s}$ & $\begin{array}{l}\text { A.3.7 (Maior); A.3.9 (Maior); } \\
\text { A.4.7(Maior); A.4.9 (Maior); } \\
\text { A.5.4 (Maior); B.6 (Maior); } \\
\text { B.8(Maior); C.1.1.6 (Critica); } \\
\text { C.1.1.13 (Critica); C.1.1.20 } \\
\text { (Maior); C.1.2.1 (Maior); } \\
\text { C.1.2.6 (Maior); C.1.4.7 } \\
\text { (Maior) }\end{array}$ & $89 \%(5 i m)$ \\
\hline & $\begin{array}{c}\text { Treinamento nas diretrizes, } \\
\text { normativas e regulamentaç̋̇es em } \\
\text { pesquisa clínica }\end{array}$ & $\mathbf{s}$ & A.4.4 (Critica); B. 8 (Malor) & 85\% (5im) \\
\hline
\end{tabular}




\section{ANEXO 2}

\begin{tabular}{|c|c|c|c|c|}
\hline \multicolumn{5}{|c|}{ Dominio - Infraestrutura (I) } \\
\hline $\begin{array}{l}\text { Ne Questão no } \\
\text { Questionário }\end{array}$ & $\begin{array}{l}\text { Objetivo da Pergunta } \\
\text { (Imax }=17)\end{array}$ & $\begin{array}{c}\text { Correlação com } \\
\text { a IN4/ANVISA } \\
\text { (S/N) } \\
\text { (Imax }=15)\end{array}$ & $\begin{array}{l}\text { Item e Classificaçăo } \\
\text { descritos no Roteiro de } \\
\text { Inspeção đa INU4/AWVISA }\end{array}$ & Frequência (96) \\
\hline 11 & $\begin{array}{l}\text { O centro possul uma farmácia } \\
\text { exclusiva para pesquisa clínica? }\end{array}$ & s & A.4.1 (Maior); A.4.2 (Maior) & $\begin{array}{l}4836 \text { possul farmácia exclusiva; } \\
30 \% \text { nảo, o produto investigacional á armazenado } \\
\text { na farmácia đa Instituiçäo; } \\
15 \% \text { nảo, o produto invertigacional ó armazenado } \\
\text { na sala de coordenação de estudos; } \\
7 \% \text { outros. }\end{array}$ \\
\hline 12 & $\begin{array}{l}\text { Existe controle de temperatura no } \\
\text { local onde o produto } \\
\text { investigacional é armazenado? }\end{array}$ & $s$ & A.4.2 (Maior) & $\begin{array}{l}33 \% \text { o controle é realizado apenas manualmente; } \\
52 \% \text { o controle é realizado manual e } \\
\text { oletronicamente; } \\
15 \% \text { o controle é realizado apenas } \\
\text { eletronicamente. }\end{array}$ \\
\hline 13 & $\begin{array}{l}\text { O local onde o produto } \\
\text { investigacional é armazenado } \\
\text { possui acesso restrito? }\end{array}$ & s & A.4.1 (Maior) & $\begin{array}{l}7 \% \text { não possui ; } \\
15 \% \text { o controle é realizado por crachá; } \\
49 \% \text { o controle é realizado por biometria; } \\
70 \% 6 \text { o controle é realizado por chave; } \\
4 \% \text { outros. }\end{array}$ \\
\hline 14 & $\begin{array}{l}\text { O centro possui Laboratório } \\
\text { específico para pesquisa clínica? }\end{array}$ & s & $\begin{array}{l}\text { A.5.1 (Informativa); A.5.1.1 } \\
\text { (Maior); A.5.2 (Informativa); } \\
\text { C.1.1.12 (Maior) }\end{array}$ & 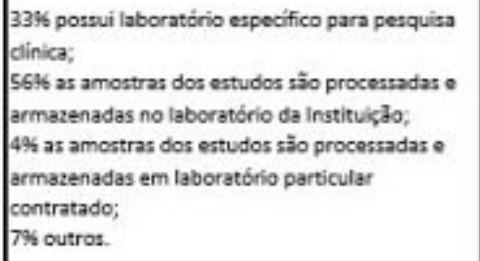 \\
\hline 15 & $\begin{array}{l}\text { Existe controle de temperatura no } \\
\text { local de armazenamento das } \\
\text { amostras de pesquisa clinica? }\end{array}$ & s & A.5.3 (Maior) & $\begin{array}{l}30 \% \text { o controle é realizado apenas manuaimente; } \\
48 \% \text { o controle é realizado manual e } \\
\text { eletronicamente; } \\
22 \% \text { o controle é realizado apenas } \\
\text { eletronicamente. }\end{array}$ \\
\hline 16 & $\begin{array}{l}\text { O local onde as amostras dos } \\
\text { estudos säo processadas e } \\
\text { armazenadas possui acesso } \\
\text { restrito? }\end{array}$ & N & Nă॰ Aplicável & $\begin{array}{l}15 \% \text { näo possul acesso restrito; } \\
15 \% \text { o controle é realizado por cracha; } \\
4 \% \text { o controle é realizado por biometria; } \\
59 \% \text { o controle é realizado por chave; } \\
7 \% \text { cutros. }\end{array}$ \\
\hline 17 & $\begin{array}{l}\text { O centro de pesquisa possui } \\
\text { consultórios especificos para } \\
\text { atendimento aos participantes de } \\
\text { pesquisa clínica? }\end{array}$ & s & A. 2.1 (Informativa) & $\begin{array}{l}81 \% \text { possui consultórios específicos; } \\
22 \% \text { os atendimentos säo realizados em } \\
\text { ambulatório e/ou enfermaria da própria } \\
\text { Instituiçăa." }\end{array}$ \\
\hline 18 & $\begin{array}{l}\text { No centro de pesquisa há local } \\
\text { para atendimento de eventos } \\
\text { adversos sérrios, incluindo } \\
\text { necessidade do internaçào? }\end{array}$ & $s$ & A.3.1 (Informativa) & $\begin{array}{l}33 \% \text { possui local para atendimento de eventos } \\
\text { adversos séries; } \\
6746 \text { o atendimento o/ou hospitalizaçäo é } \\
\text { realizado na própria Instituição; } \\
4 \% \text { É realizado instituiçäo particular contratada, } \\
4 \% \text { outros. - }\end{array}$ \\
\hline
\end{tabular}




\section{ANEXO 2}

\begin{tabular}{|c|c|c|c|c|}
\hline 19 & $\begin{array}{l}\text { O centro de pesquisa possuí } \\
\text { infrastrutura de UTI locaimente? }\end{array}$ & s & $\begin{array}{l}\text { A.3.5 (Informativa); A.3.6 } \\
\text { (Critica);A.3.6.1 } \\
\text { (Critica):C.1.1.11 (Crítica) }\end{array}$ & 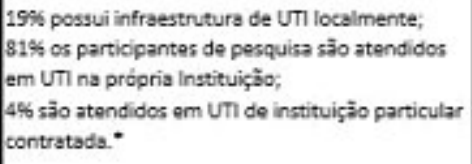 \\
\hline 20 & $\begin{array}{l}\text { O centro possui local exclusivo } \\
\text { para arquivo dos documentos dos } \\
\text { estudos clínicos em andamento? }\end{array}$ & s & A.7.1 (Maior); A.2.4 (Maior) & $\begin{array}{l}92 \% \text { possui local excluaivo; } \\
4 \% \text { arquivados na sala de coordenacalo de } \\
\text { estudos; } \\
\text { 4\% arquivados na sala do pesquisador principal. }\end{array}$ \\
\hline 21 & $\begin{array}{l}\text { O arquino de pesquisa clíica } \\
\text { possui acesso restrito? }\end{array}$ & s & A.7.2 (Maior); A.2.4 (Maior) & $\begin{array}{l}4 \% \text { não possui acesso restrito an arquivo do } \\
\text { pesquisa clínica; } \\
796 \text { o controle é realizado por crachá; } \\
85 \% \text { o controle é realizado por chave; } \\
49 \% \text { outros. }\end{array}$ \\
\hline \multirow{5}{*}{22} & $\begin{array}{l}\text { O arquivo possui Controle de } \\
\text { Umidade }\end{array}$ & s & A.7.5 (Critica) & $52 \%(\mathrm{Sim})$ \\
\hline & $\begin{array}{c}\text { O arquivo possui Controle de } \\
\text { Temperatura }\end{array}$ & s & A.7.5 (Critica) & $70 \%(\mathrm{sim})$ \\
\hline & $\begin{array}{l}\text { O arquivo possui à Prova de } \\
\text { incêndio }\end{array}$ & $s$ & A.7.5 (Critica) & $37 \%(\mathrm{Sim})$ \\
\hline & $\begin{array}{l}\text { O arquivo possui a Prova de } \\
\text { enchente }\end{array}$ & s & A.7.5 (Critica) & $2626(\mathrm{Sim})$ \\
\hline & O arquivo possui a Prova de pragas & s & A.7.5 (Critica) & $52 \%(\operatorname{sim})$ \\
\hline 26 & $\begin{array}{c}\text { O centro de pesquisa possui um } \\
\text { sistema eletrónico especifico para } \\
\text { gerencismento dos projetos de } \\
\text { pesquisa? }\end{array}$ & N & Nïo Aplicaivel & $30 \%$ (Sim) \\
\hline
\end{tabular}

\begin{tabular}{|c|c|c|c|c|}
\hline \multicolumn{5}{|c|}{ Dominio - Processos (P) } \\
\hline $\begin{array}{c}\text { N Questão no } \\
\text { Questionário }\end{array}$ & $\begin{array}{l}\text { Objetivo da Pergunta } \\
\qquad(P \max =32)\end{array}$ & $\begin{array}{c}\text { Correlaçăo com } \\
\text { a INA/ANVISA } \\
\text { (S/N) } \\
\text { (D) } \max =21]\end{array}$ & $\begin{array}{l}\text { Item e Classificaçào } \\
\text { descritos no Roteiro de } \\
\text { Inspeşào da IN4/ANVISA }\end{array}$ & Frequência (\%) \\
\hline 8 & $\begin{array}{l}\text { A instituiçăo exige que o protocolo } \\
\text { seja avalado por alguma comissåo } \\
\text { interna além do Comitê de Ética? }\end{array}$ & N & Näo Aplicável & $\begin{array}{l}\text { 33\% nào exige; } \\
\text { 44\% análise de orçamento; } \\
26 \% \text { análise do departamento onde a pesquisa } \\
\text { será realizada; } \\
\text { 30\% outros." }\end{array}$ \\
\hline 24 & $\begin{array}{c}\text { Como é o prontuário utilizado no } \\
\text { centro de pesquisa ? }\end{array}$ & $\mathrm{N}$ & ND̃o Aplicável & $\begin{array}{l}\text { 44\% totalmente em papel; } \\
\text { 41\% parcialmente em papel e parcialmente } \\
\text { eletrónico; } \\
15 \% \text { totalmente oletrónico. }\end{array}$ \\
\hline 30 & $\begin{array}{l}\text { O centro de pesquisa possui um } \\
\text { sistema de gestio de qualidade? }\end{array}$ & N & Nầ Aplicável & $\begin{array}{l}67 \% \text { näo possui; } \\
15 \% \text { possui sistema baseado nos requisitos } 1550 \\
9001: 2008 \text {; } \\
18 \% \text { outros. }\end{array}$ \\
\hline 31 & $\begin{array}{c}\text { O sistema de gestâo da qualidade } \\
\text { é certificado? }\end{array}$ & N & Năo Aplicável & $\begin{array}{l}\text { Os centros que responderam que possuiam um } \\
\text { SGQ foram questionados quanto a certificą̧äo, } \\
33 \% \text { o } 5 G Q \text { nbेo é certficado, } 45 \% \text { possuem } \\
\text { certificaçầo } 150 \text { 9001 e } 22 \% \text { outros. }\end{array}$ \\
\hline \multirow{3}{*}{32} & $\begin{array}{c}\text { O Centro de Pesquisa possui } \\
\text { Manual da Qualidade }\end{array}$ & s & B. 4 (informativa) & $52 \%(\mathrm{Sim})$ \\
\hline & $\begin{array}{l}\text { O Centro de Pesquisa possui } \\
\text { Estatuto }\end{array}$ & $\mathrm{N}$ & Nằ Aplicável & $7096(\mathrm{sim})$ \\
\hline & $\begin{array}{l}\text { O Centro de Pesquisa possui } \\
\text { Requlamento }\end{array}$ & $\mathrm{N}$ & Năo Aplicável & $78 \%(\mathrm{sim})$ \\
\hline
\end{tabular}




\section{ANEXO 2}

\begin{tabular}{|c|c|c|c|c|}
\hline 34 & $\begin{array}{c}\text { O Laboratório de Patologia Clínica, } \\
\text { onde säo realizados os eacames de } \\
\text { pesquisa clínica É certificado? }\end{array}$ & $s$ & C.1.3.2 (Maicr) & $\begin{array}{l}\text { 4\% nâo é certificado; } \\
52 \% \text { possui apenas certificaçäo nacional; } \\
22 \% \text { possul certificasăo nacional e internacional; } \\
22 \% \text { nåo soube informar. }\end{array}$ \\
\hline 36 & $\begin{array}{c}\text { O centro de pesquisa possui os } \\
\text { Procedimentos Operacionais } \\
\text { Padräo (POP) requeridos na } \\
\text { INSTRUÇ̈O NORMATIVA Ne 4, DE } \\
\text { 11/05/09 - ANVISA, que Dispöe } \\
\text { sobre o Guia de Inspesäo em Boas } \\
\text { Práticas Clinicas? }\end{array}$ & s & $\begin{array}{c}\text { A.3.7 (Maior); A.3.9 } \\
\text { (Maior); A.4.7 (Maior); A.4.S } \\
\text { (Maior); A.5.4 (Maior); B.5 } \\
\text { (Maior); B.15 (Maior); } \\
\text { C.1.1.6 (Critica); C.1.1.13 } \\
\text { (Crítica); C.1.1.20 (Maior); } \\
\text { C.1.2.6 (Maior); C.1.4.7 } \\
\text { (Maior) }\end{array}$ & $81 \%$ (Sim) \\
\hline \multirow[t]{12}{*}{37} & $\begin{array}{l}\text { O centro de pesquisa possui } \\
\text { indicadores para gest3̄o? }\end{array}$ & $\mathrm{N}$ & Nâo Aplicável & 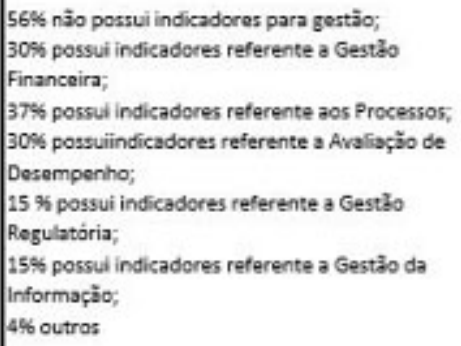 \\
\hline & \multicolumn{4}{|c|}{ O Centro de Pesquisa possui procedimento operacional, plano estratéejco, plano gerencial ou processo que contemple: } \\
\hline & $\begin{array}{l}\text { Procedimentos que zarantem a } \\
\text { confidencialidade da informaçào }\end{array}$ & s & $\begin{array}{c}\text { A.7.3 (Maior); C.2.1.11 } \\
\text { (Maior) }\end{array}$ & $89 \%$ (Sim) \\
\hline & $\begin{array}{l}\text { Procedimentos que garantem a } \\
\text { confiabilidade dos resultados }\end{array}$ & s & C.2.1.10 (Crítica) & $78 \%(\operatorname{sim})$ \\
\hline & $\begin{array}{c}\text { Procedimentes que garantem ao } \\
\text { cumprimento de normas e leis } \\
\text { aplicáveis }\end{array}$ & s & B.15 (Maior) & $89 \%(\operatorname{Sim})$ \\
\hline & $\begin{array}{l}\text { Implementasăo e revistäo dos } \\
\text { Procedimentos Operacionais }\end{array}$ & s & $\begin{array}{c}\text { A.3.7 (Maior); A.3.9 (Maior); } \\
\text { A.4.7 (Maior); A.4.9 } \\
\text { (Maior); A.5.4 (Maior); B.6 } \\
\text { (Maior); B.10 (Menor); } \\
\text { C.1.1.6(Critica); C.1.1.13 } \\
\text { (Critica); C.1.1.20 (Maior); } \\
\text { C.1.2.6 (Maior); C.1.4.7 } \\
\text { (Maior) }\end{array}$ & $81 \%$ (Sim) \\
\hline & Plano de atividades peribidicas & s & A.7.3 (Maior) & $30 \%(\operatorname{sim})$ \\
\hline & $\begin{array}{l}\text { Sistemática definida para } \\
\text { comunicasăo interna }\end{array}$ & s & $\begin{array}{l}\text { B.7 (Menor); C.2.1.6 } \\
\text { (Maior) }\end{array}$ & $44 \%$ (Sim) \\
\hline & $\begin{array}{l}\text { Flano para tratamento de } \\
\text { reclamaçöes de clientes }\end{array}$ & s & 8.7 (Menor) & $26 \%(5 i m)$ \\
\hline & Controle de documentos físicos & s & $\begin{array}{l}\text { A.7.3 (Maior); C.2.1.7 } \\
\text { (Critica) }\end{array}$ & $78 \%(\mathrm{sim})$ \\
\hline & $\begin{array}{c}\text { Controle de documentos } \\
\text { eletrónicos }\end{array}$ & $N$ & Não Aplicável & $67 \%(5 \mathrm{sm})$ \\
\hline & $\begin{array}{l}\text { Sistemática para realização de } \\
\text { cópias de segurança (backoup) de } \\
\text { toda a documentaç̧̇o eletrônica }\end{array}$ & N & Não Aplicável & $67 \%(\mathrm{sim})$ \\
\hline
\end{tabular}




\section{ANEXO 2}

\begin{tabular}{|c|c|c|c|c|}
\hline \multirow[t]{12}{*}{38} & $\begin{array}{l}\text { Plano de controle de periodicidade } \\
\text { de calibraçấo dos equipamentos }\end{array}$ & s & $\begin{array}{c}\text { A.3.7 (Maior); A.4.9 (Maior); } \\
\text { A.5.4 (Maior) }\end{array}$ & 818 (Sim) \\
\hline & $\begin{array}{l}\text { Monitoramento de desempenho } \\
\text { do estudo, por exemplo, } \\
\text { acompanhamento das taxas de } \\
\text { recrutamento, taxas de inclusio e } \\
\text { falhas de inclusío }\end{array}$ & s & B.7 (Menor) & $48 \%$ (Sim) \\
\hline & Relatório de ns̃o conformidade & s & B.7 (Menor) & $63 \%(\mathrm{Sim})$ \\
\hline & Ações Corretivas & s & B.7 (Menor) & $78 \%(\mathrm{sim})$ \\
\hline & Açóes Preventivas & $s$ & 8.7 (Menor) & $70 \%$ (sim) \\
\hline & Revisäo dos prontuários & s & A.7.3 (Malor); 8.7 (Menor) & $70 \%(\mathrm{sim})$ \\
\hline & Auditoria interna & $\mathrm{N}$ & N3o Aplicável & $48 \%$ (sim) \\
\hline & Auditoria externs & $\mathrm{N}$ & Nào Aplicóvel & $44 \%$ (Sim) \\
\hline & $\begin{array}{l}\text { Supervisāo dos submiassǒes e } \\
\text { aprovaçöes regulatória }\end{array}$ & 5 & $\begin{array}{c}\text { A.7.3 (Maior); } \\
\text { C.2.1.12(Critica); C.2.1.13 } \\
\text { (Critica); C.2.1.14 (Critica); } \\
\text { C.2.1.15 (Maior); C.3.1.7 } \\
\text { (Maice) }\end{array}$ & $70 \%$ (Sim) \\
\hline & $\begin{array}{l}\text { Avaliaçäo de adestäo acs critérios } \\
\text { do protocolo }\end{array}$ & s & $\begin{array}{l}\text { A 4.4.(Critica); A } 2.7 \text { (Maior); } \\
\text { A.4.2 (Maior); A.5.1.1 } \\
\text { (Maior); C } 2.1 .17 \text { (Critica); } \\
\text { C.2.2.2 (Critica) }\end{array}$ & $52 \%$ (Sim) \\
\hline & Avaliaçäo de eventos adversos & s & $\begin{array}{c}\text { B.15 (Malor); } \\
\text { C.2.1.12(Critica); C.2.1.13 } \\
\text { (Critica); C.2.1.14 (Critica); } \\
\text { C.3.1.9(Critica) }\end{array}$ & 7496 (Sim) \\
\hline & $\begin{array}{l}\text { Política para tratamento de } \\
\text { violaciajo de protocolo }\end{array}$ & 5 & C.2.1.24 (Critica) & $44 \%(\mathrm{sim})$ \\
\hline
\end{tabular}

- Nesta pergunta um centro poderia selecionar mais de uma alternativa. 